\title{
Na pandemia: da sala de concerto ao clube de jazz
}

\author{
Luíza Beatriz Amorim Melo Alvim \\ Universidade Federal do Rio de Janeiro \\ luizabeatriz@yahoo.com \\ Frederico Lyra de Carvalho \\ Universidade de Lille/França \\ lyrafred@gmail.com
}

\begin{abstract}
Resumo: Consideramos as modificações impostas abruptamente às apresentações musicais presenciais por causa da pandemia de COVID-19, tendo como foco as salas de concerto de música erudita e o clube de jazz, dois nichos em que a presença em recintos fechados é vista como essencial (embora o streaming, no caso da música erudita, já fosse uma realidade antes da pandemia), por causa, por exemplo, de questões de acústica ou pelo aspecto da importância da improvisação no jazz. Fazemos um pequeno apanhado histórico do desenvolvimento do modo do "ouvir atento" na música erudita, da construção de salas de concerto modernas com fins de uma melhor acústica e do surgimento dos clubes de jazz e mudanças também no modo de ouvir de seu público. Ressaltamos também algumas tentativas de reabertura de estabelecimentos durante a pandemia de COVID 19, como a Philharmonie de Paris e a Sala São Paulo, no final de 2020.
\end{abstract}

Palavras-chave: Pandemia COVID-19, Sala de concerto, Clube de jazz, Acústica, Presença.

\section{In pandemic: from the concert hall to the jazz club}

Abstract: We consider the modifications imposed abruptly to the musical presentations with public due to the COVID-19 pandemic, and, to this aim, we focus on art music concert halls and on jazz clubs. These are actually two music niches in which the presence in closed ambiences is considered essential (though streaming practices were already a reality in the case of art music much before the pandemic), because of, for example, acoustic questions or due to the importance of improvisation in the case of jazz music. We give a short historic overview of the development of a culture of "attentive listening" in art music, the construction of modern concert halls with aim of better acoustics and the emergence of jazz clubs and changes to the way of listening. We also highlight some attempts of reopening of music halls during COVID-19 pandemic, as the Philharmonie de Paris and Sala São Paulo in the end of 2020.

Keywords: Pandemic COVID-19, Concert hall, Jazz Club, Acoustics, Presence.

\section{Introdução}

Como todas as outras áreas das atividades humanas, a música foi profundamente afetada pela nova situação instaurada com a pandemia mundial de COVID-19. E consideramos aqui a música no âmbito o mais largo possível, pois todo tipo de música em todo o mundo foi diretamente afetado por este acontecimento. É certo que todos aqueles que têm a música como objeto de reflexão terão por muitos anos matéria de sobra sobre a qual mergulhar. Essa dimensão totalizante da crise já impõe de antemão uma dificuldade metodológica. Por um lado, a música aparece como sendo apenas uma parcela da dimensão social que a crise do coronavírus impôs ao mundo. Por outro lado, a crise na música é de certa forma também vivida como total. A pandemia impôs à música uma nova situação tanto no seu aspecto de produção quanto de 
reprodução. Os músicos, todos os mediadores musicais e o público de uma maneira geral se encontram todos em uma conjuntura inédita até então.

No presente momento, só parece possível olhar e tentar refletir sobre esta nova situação a partir de certas manifestações particulares. Escolhemos neste artigo nos concentrarmos sobre dois aspectos: os processos de mutação em salas de concerto de música erudita e a situação de clubes de jazz pelo mundo. Esta não deixa de ser uma maneira de retomar o antigo debate sobre a música "ao vivo" que, por causa da situação de urgência imposta pela pandemia, emergiu com uma nova roupagem. A música ao vivo é novamente problematizada só que de maneira diferente daquela do início do século XX, época da introdução e da criação do mercado do fonograma no mundo. Naquela época o sistema capitalista estava em expansão, enquanto, no momento atual, ele se encontra em crise ${ }^{1}$. A invenção de um mercado mundial pode inclusive ser vista como uma das saídas culturais para a expansão necessária ao capitalismo. Não é por acaso que Adorno (1985) identifica a música como um dos ramos privilegiados da indústria cultural nascente. Como Michael Denning mostra bem, o mercado de discos é mundial desde nascença. E o fato de ser mundial implicava que ele mudava a relação com a música em praticamente todos os lugares do mundo de forma desigual e combinada (DENNING, 2015).

Se por um lado, o fonograma, desde o seu surgimento, questionava o primado da noção de música ao vivo, ele, por outro lado, expandia os públicos e a difusão da música de uma maneira geral - mesmo que muitas vezes em detrimento de outras. A difusão dos fonogramas acompanhava a invenção de novos mercados capitalistas, dentre eles o musical que estava emergindo e em plena expansão. De uma certa maneira, ao longo das décadas seguintes, os discos e os shows e concertos se reforçavam mutuamente. Os mais diversos artistas musicais precisavam gravar discos e realizar apresentações ao vivo para existir. Sem entrar nas particularidades de cada caso, é certo que um equilíbrio entre os dois polos, mesmo que instável, ditou o processo até a virada para o século XXI. É neste momento que o fonograma passa a se converter ao formato digital. Podemos sustentar, no entanto, que esse primeiro momento da digitalização da música não mudou de forma radical a relação do público e dos músicos com a música ao vivo. Houve, evidentemente, diversos ajustes e novas práticas, mas não uma ruptura radical como na época do aparecimento do disco. Entre tempos, uma prática que emergiu sem no entanto chegar a ser dominante foi a do consumo de registros visuais de shows e concertos.

\footnotetext{
${ }^{1}$ Autores como o sociólogo alemão Wolfgang Streeck (2017) chegam a falar que esta crise dura desde meados dos anos 1970 e que desde então o sistema capitalista estaria funcionando fundamentalmente comprando tempo com dinheiro.
} 
Desde pelo menos os anos 1980 estes produtos passam a ganhar uma certa importância, sem no entanto se sobreporem aos fonogramas.

É apenas com a massificação da internet e com a chegada de dispositivos de compartilhamento de vídeos, dos quais o Youtube, fundado em 2005, é o mais conhecido, que uma nova tendência para a prática e o consumo musical parece se impor. O devir-vídeo da experiência auditiva musical parece de fato tomar forma a partir deste momento. Este processo, no entanto, se radicalizou e se acelerou de maneira espantosa com a imposição política do confinamento em decorrência da emergência sanitária em praticamente todos os países do mundo. Esta medida radical e necessária colocou novas questões, além de ter atualizado outras no que tange à experiência musical. Se com o fonograma a experiência musical se divide em dois, isto é, no concerto ao vivo e na escuta do fonograma - e em seguida um vídeo no Youtube -, o que a pandemia mostrou é que há margem para que a experiência musical se reduza para apenas um dos polos. Com a anulação de praticamente toda a música ao vivo no mundo em 2020, a experiência musical perdeu, pela primeira vez, a sua dimensão coletiva. Ela ficou reduzida ou à visita dos antigos discos - e o cada vez mais massificado acesso a dispositivos de streaming tais como o Spotify e Deezer ${ }^{2}$ - ou aos vídeos disponíveis de maneira online.

A saída que muitos músicos e instituições musicais encontraram para se manterem de certa forma vivas foi radicalizar e acelerar a imposição de uma prática que, embora já estivesse emergindo, se impunha em um ritmo lento e que ficaram conhecidas pelo sugestivo nome de lives. Não deixa de ser sintomático que o nome das transmissões online de música tente sugerir que se trataria de uma extensão da prática milenar da música ao vivo ${ }^{3}$. Não nos cabe discutir a pertinência ou não do uso deste novo termo, mas sim de reforçar que a tentativa de aumentar públicos com transmissões de música em cinemas e computadores já estava posta desde antes da pandemia. O eixo fundamental é que estas tentativas ambíguas de aumentar público e de diversificar a reprodução musical que eram, até pouco tempo atrás, aceitas apenas parcialmente e apareciam como práticas compensatórias foram, em poucos meses, incorporadas ou estão em vias de serem plenamente incorporadas à vida musical no sentido amplo. Não seria exagero apontar que esta tendência pode se impor como a prática hegemônica de produção e reprodução

\footnotetext{
${ }^{2}$ Os estudos sobre estes dispositivos são fundamentais, mas não será este o objetivo deste artigo.

${ }^{3}$ Como foi observado em outro ensaio acerca deste assunto: "O fenômeno mais impressionante da situação de pandemia musical é mesmo o das inúmeras "lives". Esse dispositivo das 'lives' revelou com ele um novo fetiche: o fetiche de algo ser ao vivo. Mesmo que seja virtualmente ao vivo, deve ser ao vivo. Ou ao menos dar a sensação de ser ao vivo, pois, se o termo fosse seguido ao pé da letra, o que se assiste virtualmente não poderia ser algo gravado ou poderia? Poderia. Mesmo que a maioria das 'lives' fossem ao vivo, parte destas não eram "live", mas previamente gravadas, muitas inclusive super produzidas.” (LYRA de CARVALHO, 2020, p. 237).
} 
musical em detrimento ao fonograma e, sobretudo, à prática da música ao vivo nas suas mais diversas variáveis. Aquilo que Adorno (2009) chamava como "escuta atomizada", sintoma da crescente dessocialização da música nas sociedades capitalistas, tende a se agravar. Devemos, no entanto, lembrar que a situação pandêmica do presente difere daquela da invenção e da introdução do fonograma. É difícil imaginar que, na era atual de crise aguda e mesmo retração dos mercados e da globalização como um todo, as "lives" possam vir a ser o mecanismo capaz de ampliar o mercado musical, elas tendem a servir, ao contrário, como compensação temporária ou até mesmo como uma saída de emergência.

Com esta configuração conjuntural em mente, tentaremos analisar as estratégias que algumas instituições ligadas a dois nichos musicais, a música erudita e em menor proporção o jazz, têm tentado implementar para continuarem a existir na situação atual com perspectivas para o futuro. Esta tendência a se transformar em uma música de nicho bastante reduzido tende a se agravar ainda mais com a virtualização crescente e as transformações presentes e futuras do mundo da música. Além disto, estes dois gêneros musicais foram responsáveis pela invenção de espaços próprios para a prática da sua música (incluindo-se, suas condições acústicas) que se veem ameaçados ou submetidos a transformações radicais que se agravaram com a pandemia. Desta maneira a sala de concerto e o clube de jazz, como um contraponto ao primeiro espaço, serão os nossos fios condutores para tentar pensar a situação da música erudita e do jazz na pandemia com vistas para o futuro da música.

\section{Aura, presença e acústica}

No seu famoso ensaio "A obra de arte na era de sua reprodutibilidade técnica", Walter Benjamin (2008) observa que a reprodutibilidade técnica faria com que a obra de arte, quando assim reprodutível, perdesse sua aura. A aura estava ligada à presença, ao aqui e agora (hic et nunc), à possibilidade (por vezes associada à dificuldade) de se estar defronte à obra original. Por muito tempo na história da humanidade só era possível ouvir música quando em sua performance. Pensando-se somente na música erudita no Ocidente, tal performance poderia ser exclusiva para a nobreza em seus palácios ou na intimidade do lar burguês, ou ainda, aberta a um público maior: obras sacras em cerimônias religiosas, os teatros de ópera a partir do século XVII, os primeiros concertos públicos no século XVIII. Com o surgimento do fonógrafo no final do século XIX e, principalmente, com a evolução dos dispositivos de reprodução sonora na forma dos discos, além da possibilidade da difusão da música pelas ondas de rádio, aquilo 
que dependia de uma performance hic et nunc pôde ser trazido para dentro de casa sem a presença dos músicos. ${ }^{4} \mathrm{Ou}$, ao menos, essa era a ideia difundida pela indústria fonográfica e radiofônica: tenha um rádio ou toca-discos e não precise sair de casa para salas de concerto e teatros de ópera. Muitos embarcaram nessa ideia e prática, mas, ainda assim, os novos meios de difusão de música não implicaram na desaparição das salas de concerto e teatros. De todo modo, o século XX, no esteio dos saraus particulares do século XIX, mostrava uma tendência de recolhimento por parte de seu público, algo que foi ampliado com a pandemia de COVID19 em 2020 e 2021.

É importante também destacar outras mudanças proporcionadas pela difusão do rádio e do disco nos anos 1940 - 1960: a transformação dos melômanos, que, antes disso, geralmente eram também músicos amadores praticantes, em, cada vez mais, melômanos cuja relação com a música se dá apenas pela escuta de discos ou rádio (MAISONNEUVE, 2014; THOMPSON, 2002; LEVINE, 1990); houve também uma crescente "patrimonialização" da música (MAISONNEUVE, 2014), entendida como um legado do passado, muitas vezes em detrimento da música contemporânea. Atualmente, a distância e distinção entre profissional e amador permanece, embora, de certa forma, haja uma difusão também da manifestação amadora pela facilidade de uso de ferramentas tecnológicas e exibição em canais como Youtube, juntamente a uma tendência de auto-exibição em redes sociais. Assim, ocorre, no final do século XX, um novo "triunfo do amador": sua diferença em relação ao profissional continua marcada e atualizada por mecanismos legitimadores, mas, por mais que sempre dependa dos algoritmos e mecanismos de busca, a difusão de sua performance nas redes é não só permitida, como cada vez mais praticada e acessada.

Um problema essencial também na mudança de hábitos e paradigmas se refere à acústica e às formas de ouvir, ou melhor, à criação de uma cultura de ouvir música, especialmente a partir do século XIX. Em seu estudo sobre teatros, salas de concerto e a relação com o público parisiense, Johnson (1995) observa que há mudanças paulatinas mas relevantes que emergem entre 1750 e 1850 . Até mais ou menos 1770, o comportamento que predominava nos teatros de ópera era o "ser visto", o exibir-se, em detrimento de uma atenção ao espetáculo no palco. Uma

\footnotetext{
${ }^{4}$ No caso da escuta acusmática de discos ou rádio, não teríamos propriamente uma performance no sentido de Zumthor (2007), pois, para ele, a performance é algo realizado necessariamente ao vivo na presença dos ouvintes.
} 
prova disso eram as frisas e camarotes reais que ficavam na área do próprio palco. ${ }^{5}$ Falava-se muito durante as óperas e geralmente não sobre elas, sendo grande a movimentação de pessoas entre os camarotes. Johnson (1995) identifica que, já na apresentação das óperas de Gluck, nos anos 1770, o comportamento do público se modifica. É quando ouvir se torna tão ou mais importante que aparecer e, nessa apreensão do que era apresentado no palco, podia-se demonstrar sentimentos de efusão emocional, com direito a lágrimas. Porém, uma verdadeira "cultura da escuta atenta" vai se consolidar como prática somente a partir de 1830, quando ocorre a predominância da música instrumental sinfônica. Assim, por mais que aplausos e gritos de "bravo" continuem comuns, vai-se a uma sala de concertos para se ter uma experiência de um ouvir concentrado, algo que, apesar de pequenas mudanças, permanece até hoje como prática dominante (ao menos, até a pandemia de COVID-19).

Pode-se associar essa interiorização do ouvir dentro de um espaço adequado a ele ao “declínio do homem público" considerado por Sennett (1988) como resultado da ascensão da burguesia no século XIX, momento em que o lar burguês se torna símbolo da estabilidade e da ordem em contraposição ao espaço público. Ainda que o teatro e a sala de concerto sejam partes do espaço público, surge todo um código de comportamento adequado dentro deles para domesticá-los. Nessa nova cultura do ouvir atento, em seu estudo sobre o público norteamericano e sua relação com a música erudita, Levine (1990) também observa, na passagem do século XIX para o século XX, uma mudança no sentido de sua sacralização. Ou seja, ir a um concerto é como ir a um templo religioso ouvir algo extremamente elevado e que demanda todo o respeito e atenção dos presentes. Daí um silêncio digno de algo rodeado de uma aura.

Thompson (2002) observa, por outro lado, como parte importante dessa mudança para a cultura do ouvir concentrado, a transformação no estilo de construção de novas salas de concerto na virada do século XX, no sentido de uma busca de fundamento num pensamento acústico com fins de garantir uma boa audição para o público. O paradigma evocado pela autora é o do Symphony Hall em Boston, inaugurado em 1900. Embora seguindo o modelo retangular da Gewandhaus de Leipzig (a segunda, que foi inaugurada em 1884 e destruída na Segunda Guerra Mundial; a atual é de 1981), considerado acusticamente bem-sucedido (Fig. 1) e

\footnotetext{
${ }^{5}$ Um resquício disso pode ser visto ainda em nossos teatros brasileiros mais tradicionais como o Teatro Santa Isabel em Recife, embora a maioria tenha sido construída já no século XX (caso do Theatro Municipal do Rio de Janeiro, inaugurado em 1909). Vale ressaltar que a Opéra Garnier de Paris foi construída no final do século XIX e tem essa mesma arquitetura.
} 
bastante utilizado em outras salas de concerto europeias do final do século XIX ${ }^{6}$, a sala de Boston teve ainda por cima o diferencial de ter tido a orientação de um especialista em acústica, Wallace Sabine. Embora a cultura da escuta silenciosa e concentrada nas salas de concerto fosse a norma no final do século XIX e houvesse já uma preocupação com a acústica das salas, os estudos de Sabine, aplicados na construção do Boston Symphony Hall, é que demonstraram a importância do tempo de reverberação, cujo valor ideal variava com o tipo de música (somente orquestral, vocal etc.) e período histórico (com valores bem diferentes do Barroco ao Romântico). Influenciava também no tempo de reverberação o próprio corpo do espectador, sendo fator importante para o seu cálculo se a sala estivesse cheia ou vazia (THOMPSON, 2002; JASPER, 2020).

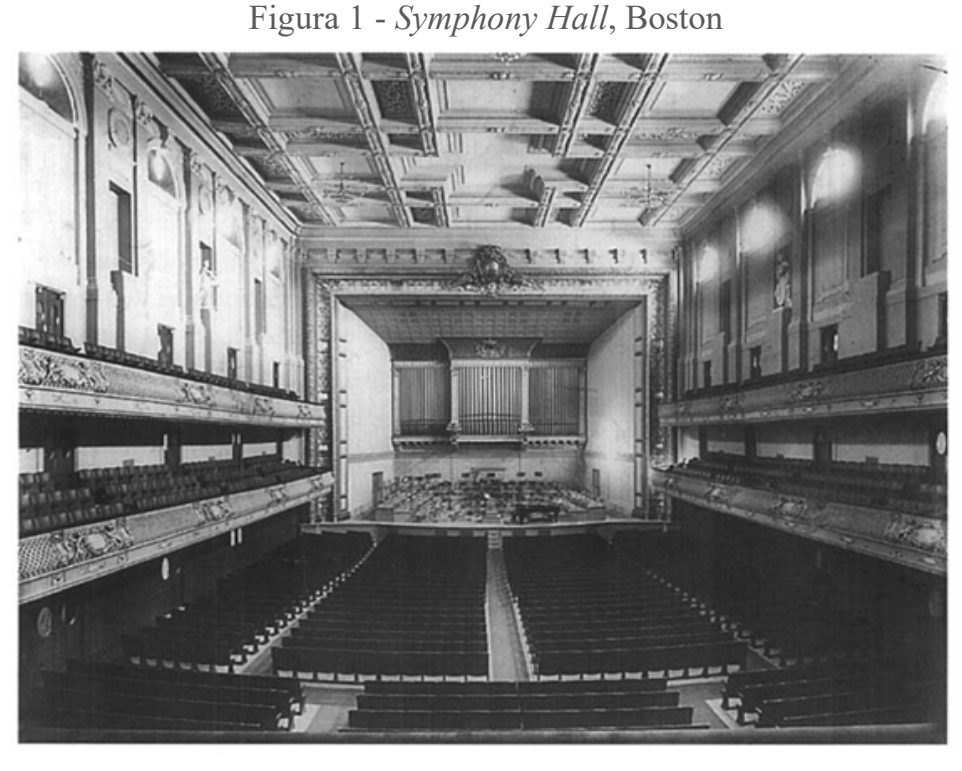

Fonte: THOMPSON, 2002, p.14

Na passagem do século XVIII para o XIX, já havia ocorrido um aumento considerável do tamanho dos teatros, que, se antes eram mais restritos ao rei e à nobreza, passavam a atender um público pagante bem maior. $\mathrm{O}$ aumento do tamanho dos teatros é exemplificado por Thompson (2002) com os dados da Ópera de Margrave em Bayreuth, de 1748, da tradição real, com capacidade para 450 lugares, ao passo que o Teatro Alla Scala de Milão, construído 30

\footnotetext{
${ }^{6}$ Como exemplos de outras salas de concerto europeias no formato retangular (também conhecido como "caixa de sapato"), com assentos para o público nas suas partes elevadas, ainda presentes até hoje e cuja acústica é considerada muito boa, temos a Koninklijk Concertgebouw de Amsterdam, inaugurada em 1888, e a Musikverein de Viena, inaugurado em 1863. No caso da Concertgebouw de Amsterdam, há também assentos utilizados para o público atrás do palco, característica das salas mais modernas, no modelo circular com várias plataformas (chamado de "vinhedo"), como a Philharmonie de Berlim, que detalharemos mais adiante.
} 
anos depois, na tradição comercial, passou a ter a capacidade de acolher 2.300 pessoas. $\mathrm{O}$ desafio proposto aos arquitetos na segunda metade do século $\mathrm{XX}$ foi o projeto de salas de concertos para muitas pessoas (mais do que a média das salas de concerto retangulares) e com uma acústica excelente, o que, para além de todo o processo de sociabilidade envolvido na ida a um concerto, tornasse ainda mais justificável frente à possibilidade de vê-los transmitidos na televisão e no rádio (ou, mais recentemente, pela Internet). A se considerar que a Elbphilharmonie de Hamburgo foi inaugurada em 2017, nem mesmo a Internet foi vista como um concorrente às salas de concerto europeias, que ainda contam com o turismo musical especializado para manterem-nas cheias. Algo que só parece ter efetivamente mudado com as medidas restritivas impostas pela pandemia de COVID 19.

Um marco para as salas de concertos modernas foi a construção da Philharmonie de Berlim, inaugurada em 1963, num formato arquitetônico circular, com 2.230 assentos (Fig. 2). O projeto foi idealizado por Hans Scharoun, representante de um "modernismo orgânico", cujos princípios buscavam a conformidade com o local e propósitos (no caso da Philharmonie de Berlim, ela foi construída num local cheio de espaços vazios, ainda sob efeitos da destruição da Segunda Guerra Mundial e da divisão da cidade pelo Muro de Berlim), seguidor de um modelo emancipatório, que objetivava colocar o público em volta dos músicos, diminuindo as distâncias entre eles, além da finalidade utópica de desmantelamento de hierarquias sociais, tão presentes em outras salas de concerto (JASPER, 2020). Portanto, embora a acústica da Philharmonie de Berlim seja hoje bastante estimada, este não era o objetivo principal do projeto (ainda que houvesse uma equipe especializada trabalhando junto a Scharoun), que se voltava principalmente para a criação de um "espaço íntimo que enfatizava aspectos sociais da experiência coletiva da música" (JASPER, 2020, p. 1124). Ou seja, a sala devia ser ao mesmo tempo capaz de receber um grande público, mas sem perder o caráter de intimidade e contar com uma boa acústica. 
Figura 2 -O formato em "vinhedo" da Philharmonie de Berlim

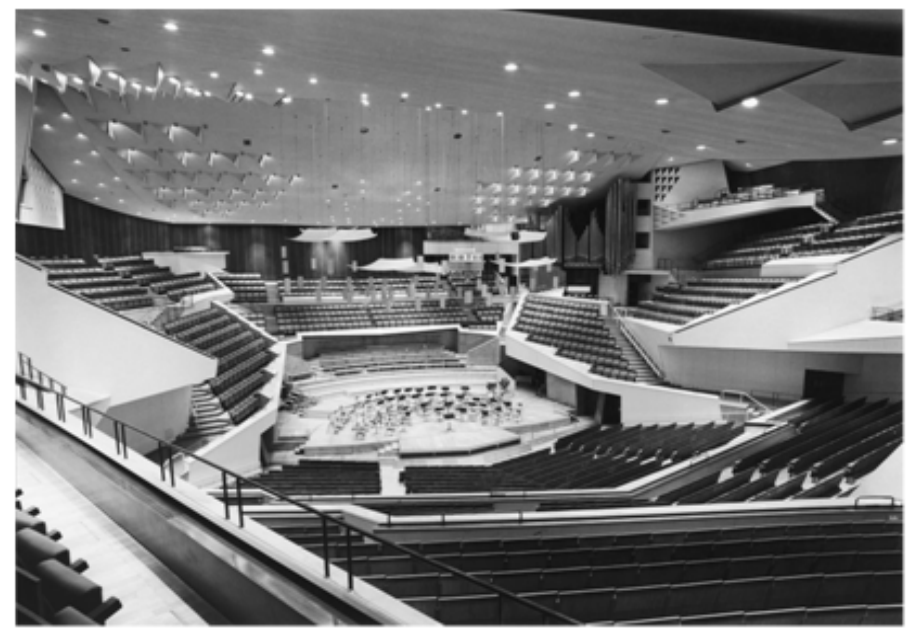

Fonte: JASPER, 2020, p. 1125.

No entanto, o idealismo social e de "acústica igualitária" do modelo de Scharoun não se sustenta, como observou o especialista em acústica Leo Beranek (1994; 2016), já que há diferenças acústicas significativas entre sentar-se nas partes laterais e detrás da orquestra em relação aos espectadores que se sentam na frente, especialmente em concertos com voz e/ou piano. Além do mais, há grande diferença do que se vê, tanto para os espectadores desses lugares (que perdem parte da visão dos músicos e, no caso daqueles que ficam atrás do palco, não veem o rosto de cantores solistas), quanto para aqueles que se sentam nas partes mais elevadas e distantes do palco.

Após o exame de várias salas de concerto, Beranek (2016) continua preferindo o formato retangular de salas como a Musikverein de Viena e Concertgebouw de Amsterdam onde, a partir de dados de sua própria pesquisa e de outros autores, verificou que a qualidade sonora é quase uniforme em cerca de $90 \%$ dos assentos. Mesmo assim, há diferenças de clareza e intensidade sonora, dependendo se o assento é nas primeiras filas da platéia (maior clareza) ou no balcão de fundo do segundo andar (um som mais "envelopante"). Ainda assim, o modelo da Philharmonie de Berlim foi adotado em várias salas inauguradas no século XXI na Europa, como a Philharmonie de Paris (inaugurada em 2015) e a já citada de Hamburgo (em 2017), ou ainda em outros continentes, como o Walt Disney Concert Hall em Los Angeles (de 2003).

Chama a atenção, como já mencionado, que, mesmo com o aumento de possibilidades de se assistir a um concerto em casa até mesmo em tempo real por streaming, em grandes cidades como Paris e Hamburgo não se perdeu de vista a viabilidade da construção de uma grande sala com capacidade para grande público. No caso das duas, embora com preços de ingresso de 
valor elevado (mesmo levando em conta o salário médio dessas cidades europeias), era comum estarem lotadas. Além do público local, muitas pessoas viajavam especialmente para assistirem concertos ao vivo nessas salas. Ou seja, o streaming não acabou com o desejo de se assistir um concerto ao vivo, que implica muito mais do que a música em si (adquirível no streaming), a aura de se ver os intérpretes no mesmo espaço, a boa acústica das salas e a sociabilidade dos melômanos. Ao menos, era assim antes da pandemia.

Pois, bem antes da pandemia, o mundo clássico já havia investido no streaming como forma de expandir seu público, restringido pelos limites físicos da sala e do local, ampliando também seus ganhos. A pioneira, mais uma vez, foi a Philharmonie de Berlim em 2009, com sua plataforma Digital Concert Hall, que possibilita tanto o streaming de concertos da sala em tempo real para a casa dos consumidores quanto o consumo de gravações on-demand. Já no mundo da ópera, as transmissões começaram ainda antes, em 2006, com o lançamento do Metropolitan Opera House da série Metropolitan Opera: Live in HD. Assim, havia a diferença dessas transmissões quanto às de Berlim no seu alvo, já que elas foram para as salas de cinema, com a utilização de seus recursos sonoros de espacialização do som, como o sistema Dolby. Portanto, embora estando ainda numa situação de reprodutibilidade mecânica, sem a copresença de espectador e artista no mesmo espaço, a situação, de certa forma, se aproxima daquela do teatro. Afinal, sai-se de casa para um ambiente fechado, com acústica controlada, e possibilidade de sociabilidade com conhecidos e outros que compartilham um gosto comum. É fato curioso que, em muitas das transmissões do Metropolitan, mesmo naquelas que não eram ao vivo, o público do cinema aplaudia ao final, por mais que tivessem plena consciência de que os artistas em Nova York não poderiam ouvi-los.

Já no caso das transmissões da Philharmonie de Berlim, o aspecto da sociabilidade não existe, enquanto se depende, em termos de acústica, do quanto aquele determinado indivíduo investiu em sua aparelhagem particular de home theater. Esse aspecto da diferença da capacidade tecnológica acústica individual de cada lar ficou bastante evidente durante a pandemia do coronavírus. Por outro lado, podemos especular se a baixa qualidade sonora em grande parte dos dispositivos reprodutores não levaria a uma “regressão da audição". Se Adorno (1999) reivindicava essa tese no final dos anos 1930 referente à escuta desconcentrada proporcionada pelos meios de comunicação de massa da época, podemos dizer que, além do aspecto da falta de concentração ainda reinante pelo fato de que a música é consumida no 
ambiente doméstico, em tese não controlado, há uma perda acústica, algo ainda mais identificável depois de tudo o que se investiu na acústica de salas.

\section{Os desafios da volta às salas de concerto durante a pandemia}

Com todo o investimento feito nas modernas salas de concerto, especialmente na Europa, a permanência da dinâmica da música feita com presença de público e todos os prejuízos trazidos à música para grandes efetivos ao serem fechadas as salas de concerto, seria no mínimo estranho que se aceitasse a pandemia sem buscar soluções para além das "lives", ou seja, a busca de formas de, com adaptações, se voltar à abertura das salas.

Ainda no início da pandemia, um alarmismo tomou conta de todos: será que nunca mais teremos a experiência da sala de concerto? Diante do conformismo geral com as "lives" e o "novo" modelo, alguns músicos importantes expressaram seu temor em reportagens jornalísticas. Embora tenha organizado um festival online no início de julho de 2020 com o sugestivo nome Distance/Intimacy, o renomado pianista e regente Daniel Baremboim não deixou de manifestar sua apreensão com o futuro, mesmo dizendo acreditar que os espetáculos com público serão possíveis novamente: "Se eu pensasse que nunca mais poderia reger o ciclo do Anel [dos Nibelungos, de Wagner] ao vivo novamente, não posso dizer o que faria." Baremboim também acusou o maior rigor com que salas de concerto foram consideradas pelas leis de segurança sanitária em comparação a outros espaços fechados, como restaurantes, apontando que isso refletiria um problema maior: a decadência da educação musical e falta de vontade política (KETTLE, 2020).

Com um arrefecimento da pandemia na Europa na metade do ano de 2020, mesmo ainda sem vacinação, algumas salas de concerto conseguiram voltar ao modo presencial com público no segundo semestre. Foi o caso da Philharmonie de Paris, em setembro de 2020, o mês normal de abertura das temporadas da Philharmonie, após as férias de verão europeias. Assim, no mês de setembro de 2020, além de um festival de jazz no início do mês ${ }^{7}$, foram oito concertos de música clássica na Philharmonie de Paris, sem contar os que são repetidos no dia seguinte, caso habitual dos concertos da Orquestra de Paris, residente do espaço. Além de adaptarem os programas com o intuito de não haver intervalo (durando no total pouco mais de uma hora até uma hora e meia), houve a implementação de medidas de distanciamento do público e o

\footnotetext{
${ }^{7}$ É importante dizer que, além da música clássica, a Philharmonie abre seus espaços ao jazz e à assim chamada world music, normalmente com fins-de-semanas dedicados à música de um determinado país ou região do mundo.
} 
cancelamento do serviço de guarda de casacos e volumes. Alguns concertos com orquestras estrangeiras foram anulados, como o programa da London Symphony Orchestra com regência do britânico Simon Rattle, assim como o de solistas estrangeiros, como o violoncelista Yo Yo Ma. Outros músicos foram substituídos, como o regente Christoph von Dohnányi por Gianandrea Noseda. Substituições são comuns, mas não sabemos se esta foi em função de problemas de fechamento de fronteiras ou dificuldades de deslocamento por conta da pandemia.

O que se pode notar dos programas da Philharmonie de Paris (que podem ser consultados no site da instituição) é uma prevalência maior de músicos franceses ou que moram na França. Este não é propriamente um problema para a França, um dos grandes centros de música clássica do mundo, para onde muitos artistas estrangeiros em formação se dirigem para estudar e onde outros de renome preferem se instalar por diminuírem, assim, os deslocamentos entre as principais salas de apresentação, num circuito que inclui o Concertgebouw de Amsterdam, salas de Londres e Bruxelas, distâncias que podem ser percorridas por trem ou ônibus, além de viagens curtas de avião de Berlim, Viena e para a Itália. Com o fechamento de fronteiras e dificuldades para viagens de longa distância, a pandemia expõe mais essa imensa desigualdade entre diferentes países, como tantas outras já presentes anteriormente. Salas brasileiras, por exemplo, não contam com a mesma facilidade de circulação de músicos, embora, como veremos, a Sala São Paulo teve um caráter de exceção.

O mês de outubro de 2020 na Philharmonie de Paris parecia indicar que tudo ou quase tudo voltaria a ser como antes. Foram 18 concertos de música erudita (estamos excluindo as repetições e os concertos de outros gêneros, além do festival Nuits Blanches, que tem características especiais), praticamente o mesmo número de 2018, com 20 concertos, incluindo um Festival Jerusalém e vários estrangeiros, apesar dos cancelamentos do concerto da Orquestra de Shangai, da Camerata Salzburg, do grupo de Jordi Savall, de uma ópera contemporânea em versão concerto e da Orquestra de Kinshasa. Alguns concertos tiveram durações grandes e intervalos, como a impressionante versão concerto de $4 \mathrm{~h} 25 \mathrm{~min}$ da ópera Khovanchtchina, de Modest Mussorgski, regida por Valery Gergiev, com orquestra e coro do Teatro Mariinsky de São Petersburgo e cantores russos, no dia 4 de outubro de $2020 .{ }^{8}$ Além desse espetáculo, houve concertos de quartetos de cordas e a ópera Dienstag aus Licht, de Karlheinz Stockhausen, com 3h25min de duração e um intervalo. Mesmo com o toque de

\footnotetext{
${ }^{8}$ Segundo informação de uma pessoa que esteve no concerto, houve um intervalo de 45 minutos, em que as pessoas foram orientadas a permanecerem de preferências em seus lugares, a não ser para irem aos banheiros. Os cafés estavam fechados. A orquestra e o coro tiveram uma redução no seu efetivo total.
} 
recolher imposto a partir da segunda quinzena do mês, os horários dos espetáculos foram adiantados e eles puderam ser realizados. A partir de novembro de 2020, com novas medidas de restrição, os concertos com público foram todos cancelados e a sala passou a fazer transmissões online, só voltando a reabrir (e, com muitos concertos anulados ou postergados) na segunda metade de maio de $2021^{9}$.

No caso do Brasil, outubro de 2020 também foi um bom mês para os frequentadores de salas de concerto de São Paulo. Depois de manter uma temporada online, a Sala São Paulo reabriu para o público em 15 de outubro de $2020^{10}$, com os concertos de sua orquestra residente, a Orquestra Sinfônica do Estado de São Paulo (OSESP), seguindo os mesmos protocolos de uso de máscara, redução de público e ajuste de programas para um tempo menor de duração dos concertos sem intervalo. Segundo informações colhidas com frequentadores, após alguns primeiros concertos, o espaço do café chegou a abrir com limitações e distanciamento entre as mesas. O público dos primeiros concertos foi limitado aos assinantes, mas, aos poucos, houve a retomada até de alguns programas para distribuição de ingressos da OSESP, como o Passe Livre Estudantil. É importante dizer que a OSESP tem um regente estrangeiro contratado desde 2019, o suíço Thierry Fischer, presente em vários desses concertos. Além de Fischer, outro estrangeiro que colabora frequentemente com a OSESP e participou de concertos em janeiro e fevereiro é o regente inglês Neil Thompson, responsável pela Orquestra Filarmônica de Goiás (a orquestra teve vários músicos demitidos por problemas contratuais em 2020 e, no início de 2021, retomou apenas atividades educativas online). Portanto, Thompson já tinha residência no Brasil. Mas chamou a atenção a presença do pianista francês Alexandre Tharaud em concertos com orquestra ou recital em janeiro de 2021 (Tharaud teve um recital seu cancelado na Philharmonie de Paris, concerto que teria sido no dia 04 de novembro de 2020).

A Sala São Paulo ficou aberta até o final de fevereiro. Desde dezembro já havia um novo recrudescimento da pandemia no Brasil, mas o fechamento só ocorreu mesmo num momento

\footnotetext{
${ }^{9}$ Vale destacar que, no momento da escrita do artigo, grande parte da população parisiense já está vacinada contra o vírus da COVID-19.

${ }^{10}$ Nas outras poucas capitais brasileiras com temporadas de concertos regulares, apenas a sala Minas Gerais em Belo Horizonte chegou a abrir para o público pouco depois, fechou novamente e reabriu em 2021. No Rio de Janeiro, a Sala Cecília Meireles manteve temporada digital em 2020, só abrindo para o público em 17 de abril de 2021 (concerto para canto e piano, tendo durado uma hora e meia sem intervalo, seguindo protocolos de distanciamento), depois de muitos adiamentos da retomada presencial de sua temporada. O Theatro Municipal do Rio de Janeiro permanece sem concertos ou óperas com público. Insistimos que esse item do artigo se refere à abertura da sala para o público, permitindo que se desfrute do concerto ao vivo, com as condições de acústica de uma sala moderna. Os concertos com transmissão digital já existiam em muitas salas, tal como analisado no item anterior, com todos os questionamentos que lá apontamos.
} 
próximo ao colapso do sistema de saúde, no final de fevereiro de 2021. Foi reaberta ao público na segunda metade de abril de 2021, embora, diferentemente de Paris, grande parte da população ainda não estivesse vacinada e os números de casos e mortes por COVID-19 ainda permanecessem altos.

\section{Um breve contraponto pelos clubes de jazz}

Uma outra perspectiva para se pensar a situação musical da pandemia pode ser encontrada em um outro dispositivo musical que se encontra mais e mais sob ameaça de sobrevida: o clube de jazz. Se este gênero musical já vinha perdendo público e espaço próprio ao longo dos últimos anos, a pandemia parece ter agravado ainda mais a situação. Muitos clubes fecharam, boa parte tem o futuro incerto e o tipo de frequentação, bastante diferente da sala de concerto, é de futuro incerto para o mundo pós-pandêmico.

O “dispositivo clube de jazz”, como diz Olivier Roueff, apareceu ainda antes da Segunda Guerra mundial como um lugar dedicado à música e à dança. É apenas após este acontecimento catastrófico de dimensões mundiais e da emergência do estilo bebop com a figura paradigmática do saxofonista Charlie Parker que o clube de jazz se transforma em um local destinado sobretudo à escuta musical. A invenção deste dispositivo musical implicou um novo tipo de escuta de certa forma análogo aos primórdios da ópera, observa Roueff (2003, p. 326). O público vai ao clube "ouvir a música da orquestra sob o fundo de conversa e o tinir dos copos; e a conversa com amigos ou conhecidos contra um fundo de música jazz". Desde então se instaura uma certa estetização social do espaço do clube, parte do público compõe uma rede fiel enquanto outra frequenta ocasionalmente. Embora sejam locais destinados à música, o público de jazz quase nunca se encontra mergulhado num silêncio absoluto. Boa parte dos clubes de jazz servem refeições e bebidas durante o concerto. Lembremos que uma cena clássica encontrada nos mais diversos filmes é a do músico, e consequentemente do público, em torno de uma cortina de fumaça durante a música. Há uma prática de escuta particular ao jazz que difere substancialmente da sala de concerto.

No seu estudo de campo sociológico, Roueff encontrou dois extremos em dois clubes franceses. No clube Pelle-Mêle, localizado na cidade de Marseille, de perfil mais tradicional, o público era mais reativo à música. Ele participava ativamente do concerto com aplausos nos solos e também conversando entre si durante a música. No clube Instant Chavirés, por outro lado, o público estava mais próximo daquele da música erudita. De perfil avant-gardiste a 
programação deste clube localizado em Montreuil, subúrbio de Paris, impunha uma escuta atenta e silenciosa ao seu público. Embora situado entre estes extremos, o público num clube de jazz é, não obstante, mais informal do que em uma sala de concertos tradicional. Isto se deve, entre outras coisas, à arquitetura do lugar, observa Laurent Cugny (2002). Capaz de acolher um público de número reduzido, indo de poucas dezenas até no máximo três centenas, o clube de jazz, uma variante do cabaré diz o musicólogo, é apto a criar um ambiente musical íntimo distinto daquele das salas de concerto de maior envergadura. Não é raro encontrar alguns músicos um pouco mais audaciosos e se arriscando mais nos seus improvisos nos clubes do que nas salas de concerto ou nos festivais. Cugny dá como exemplo a compilação de registros realizados em 1965 do quinteto de Miles Davis no Plugged Nickel, um clube de Chicago e dos inúmeros álbuns gravados no Village Vanguard, um dos principais clubes de Nova York. Por outro lado, ao mesmo tempo que considera o clube de jazz como um dos locais fundamentais para o jazz, o autor observava que já nos anos 2000 o dispositivo se encontrava em crise.

De maneira semelhante às salas de espetáculo, como a Philharmonie de Paris, os clubes de jazz franceses receberam ajuda financeira do Centro Nacional da Música, órgão do governo, para não fecharem. Esta foi uma medida fundamental durante o primeiro e o segundo confinamento, pois eles impunham a interdição de qualquer atividade artística. Neste período, os clubes estavam totalmente fechados. Nos meses de julho a outubro, período do verão e início do outono, quando houve um certo relaxamento - mas nunca abolição - das medidas de distanciamento social, os clubes puderam operar de maneira parcial. De maneira geral, os concertos aconteceram com a presença de um público reduzido, sendo obrigatório o uso de máscaras. Mais tarde, quando o toque de recolher foi instituído por volta da metade de outubro de 2021, os clubes tiveram novamente que se adaptar. O clube Sunset-Sunside, por exemplo, antecipou os horários dos concertos. Tendo em vista que o horário imposto para o encerramento das atividades era de $20 \mathrm{~h}$, ele passou a programar shows às $16 \mathrm{~h}$ e às $18 \mathrm{~h}$ nos finais de semana. Duc des Lombards, um outro clube importante da cidade, preferiu fechar as portas e aguardar que as regras sejam flexibilizadas (YANKEBIAN, 2020). Embora de maneira ainda menos determinante do que a que acontece com a Philharmonie, os clubes de jazz da cidade de Paris também dependem da circulação dos turistas, o que além de tudo tem também aumentado o preço das suas entradas.

A situação é mais dramática nos Estados Unidos, terra de origem do jazz. O The Blue Whale, um dos principais clubes de Los Angeles, voltado sobretudo para o jazz contemporâneo, 
anunciou no final de dezembro de 2020 que estava fechando definitivamente as suas portas. É uma grande perda para um uma cidade carente de lugares semelhantes, observou o jornalista Nate Chinen (2020). Não muito longe dali, o Hermosa Beach's Lighthouse Cafe, que acolheu no passado Miles Davis e Chet Baker, está conseguindo sobreviver pelo simples fato do seu proprietário ter vendido o clube para um novo dono. Desde que reabriu, no entanto, o clube tem dedicado sua programação a uma variedade cada vez maior de gêneros para além do jazz. De certa forma, os próprios clubes de jazz contam com cada vez menos jazz nas suas programações (GUZMAN, 2021). Situação mais dramática, no entanto, vive a capital norte-americana. Washington assistiu ao fechamento dos clubes Sotto, Alice's Jazz and Cultural Society, Tesfayes e Twins desde que a pandemia invadiu a cidade que abriga o Capitólio. Como se já não bastasse, o Blues Alley, último clube inteiramente dedicado ao gênero na capital, está à procura de um novo lugar para poder se estabelecer. Os músicos lamentam este fim acelerado dos locais artísticos e de trabalho que nem um programa de ajuda nacional colocado em prática pelo governo federal norte-americano tem conseguido impedir (BERKON, 2021).

A situação não é melhor na cidade de Nova York, a capital internacional do jazz. O caso do ShapeShifter Lab é um dos mais dramáticos. Espaço dedicado à criação musical do jazz contemporâneo e dirigido pelo baixista Matthews Garrison, filho de Jimmy Garrison membro do quarteto clássico de John Coltrane, o ShapeShifter Lab entrou com um pedido de crowdfunding na tentativa de se manter ativo e de continuar existindo em uma eventual situação de pós-pandemia ${ }^{11}$. Um outro caso é o do mítico clube Birdland. Atualmente na sua quarta encarnação o Birdland, que abriu pela primeira vez em 1949, corre sérios riscos de fechar definitivamente as suas portas. Depois da sua primeira encarnação, que durou até 1965, o clube ficou fechado por mais de 20 anos, reabrindo as suas portas apenas em 1986. Foi necessário um renascimento, de certa forma institucional do jazz, para que o clube tivesse condições financeiras de reabrir.

Cada vez mais os clubes famosos da cidade se encontram inseridos em uma nova configuração que passa pela indústria do turismo, por fundações e por um circuito cada vez mais elitizado desta música. Não por acaso, sabendo deste papel social de atração musical e turística, o seu atual proprietário reclama com vigor do tratamento dispensado pela cidade de Nova York às casas de música, sobretudo aos clubes de jazz. Ele assinala que o eventual fechamento de um dos clubes mais tradicionais da cidade seria, ainda por cima, um péssimo

\footnotetext{
${ }^{11}$ Ver o site do espaço: https://www.shapeshifterlab.com/
} 
sinal dado a toda a comunidade do jazz. Ao final, não se trataria apenas de um local isolado, mas da totalidade da vida musical da cidade, particularmente do jazz (GOPNIK, 2021). O destino de outro dos mais importantes clubes da cidade foi, no entanto, selado, o Jazz Standard (Fig, 3) fechou definitivamente as suas portas no final de novembro $2020^{12}$ (TSIOULCAS, 2020). Por fim, aquele que é talvez o clube mais famoso do mundo, o Village Vanguard, passou a disponibilizar no seu site uma série de concertos que podem ser adquiridos online ao custo de um ingresso. Paga-se assim por um show livestream mais ou menos o mesmo preço que se pagaria por uma entrada de fato no clube. Até o presente momento todos os concertos disponibilizados foram organizados especialmente para este novo formato. Com os músicos aparecendo mascarados e as imagens, evocando o auge do gênero nos anos 1950 e 1960, em preto e branco o livestream do Village Vanguard possibilita, ao menos por um instante, que o absoluto presente seja vivido como se fosse o passado.

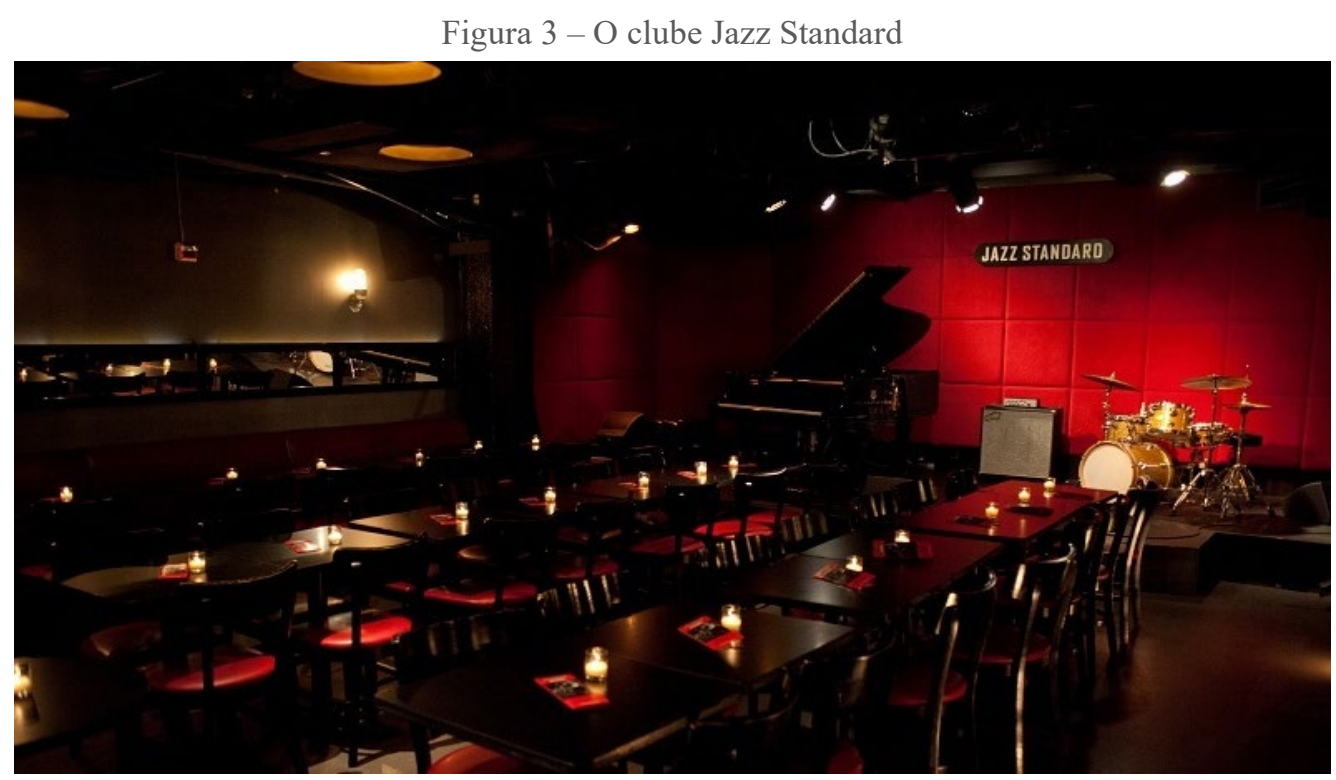

Fonte: OLCOTT, 2020, não paginado.

No entanto, como foi bem observado por Ben Sisario e Giovanni Russonello (2020), o jazz e o músico de jazz têm uma dependência maior do concerto presencial em relação a outros gêneros, pois se fundamenta, sobretudo, na improvisação. Além disso, diferentemente de dispositivos como as salas de concerto que são, na maioria das vezes, públicas ou parcialmente

\footnotetext{
${ }^{12}$ Em um depoimento bastante emotivo a antiga garçonete do Jazz Standards, Emily Olcott (2020), descreve um pouco das suas experiências e lembranças do clube no qual trabalhou durante seis anos.
} 
públicas, ${ }^{13}$ o clube de jazz, o local por excelência para esta música, por ser um dispositivo inteiramente privado se encontra sob sério risco de desaparecimento devido à dificuldade de manutenção e de se adaptar ao confinamento.

\section{Considerações finais}

Devido à situação imprevisível da pandemia, qualquer conclusão só pode ser provisória. Em se tratando tanto das salas de concerto quanto dos clubes de jazz não poderia ser diferente. Do lado dos clubes de jazz a tendência de agravamento da crise tende a se confirmar. Como Cugny já observava, estes dispositivos vêm diminuindo de quantidade e as suas programações têm sido cada vez mais ecléticas indo para além do jazz. Parece claro que uma parte considerável dos clubes de jazz no mundo tendem a fechar as portas. Resta saber como será o funcionamento daqueles que continuarão ativos. Eles provavelmente se tornarão ainda mais caros e desta maneira elitistas. O circuito turístico das grandes cidades globais poderá englobálos de maneira ainda mais clara. Por outro lado, uma tendência dominante parece apontar para uma dissociação ainda maior entre a música jazz e o dispositivo clube de jazz. Uma outra possibilidade é que o streaming e todas as suas variantes seja definitivamente incorporado no funcionamento quotidiano dos clubes.

No caso das salas de concerto e dos teatros de ópera, de maneira geral, muitos ainda se encontram num compasso de espera do momento em que haja condições e permissões de reabertura, outros já reabriram, com redução de público ou não, mas a cautela se mantém. Há muita incerteza no meio, especialmente no caso daqueles, como o Metropolitan Opera House, que não contaram com ajuda do governo durante o fechamento, o que levou vários músicos a pedirem aposentadoria precoce (JACOBS, 2021). Em termos de auxílio financeiro, a situação parece ter sido melhor na França e na Alemanha, mas não se sabe o que acontecerá com o prolongamento da crise em termos das temporadas, de público e de possíveis demissões, caso a pandemia persista com novas ondas e novos fechamentos.

A tendência é que o streaming continue e se expanda para a atividade de várias salas, até mesmo porque ele já era uma realidade pré-pandêmica. Por outro lado, dificilmente se abdicará do dinheiro investido na construção de salas como a Philharmonie de Paris e outras salas

\footnotetext{
${ }^{13}$ No caso de algumas salas aqui evocadas, a Philharmonie de Paris teve sua construção financiada em parte pelo Ministério da Cultura francês e pela prefeitura de Paris, além de um aporte menor da região Île de France. No caso da Sala São Paulo, foi uma obra do governo do Estado de São Paulo e desde 2005 a sala é administrada pela Fundação OSESP, no modelo de organização social (OS), numa parceria público-privada.
} 
modernas. Além do mais, há o aspecto aqui desenvolvido da importância da acústica e da aura da presença para a música erudita. A reabertura da Philharmonie de Paris e da Sala São Paulo no segundo semestre de 2020 (sem vacinação e já na expectativa de uma segunda onda, prevenida por cientistas, no caso de Paris, e, em plena pandemia, no caso paulista) mostra que há um desejo, ao menos, de que o mundo pandêmico ou pós-pandêmico não se restrinja aos espaços digitais.

\section{Referências}

ADORNO, Theodor. Dialética do Esclarecimento. São Paulo: Zahar, 1985.

ADORNO, Theodor. Introdução à sociologia da música. São Paulo: Unesp, 2009.

ADORNO, Theodor. O fetichismo na música e a regressão da audição. In: Os pensadores - Textos escolhidos. São Paulo: Nova Cultural, 1999.

BENJAMIN, Walter. A obra de arte na era de sua reprodutibilidade técnica. In: BENJAMIN, Walter. Magia e técnica, arte e política. Ensaios sobre Literatura e História de Cultura. 7 ed. São Paulo: Brasiliense, 2008.

BERANEK, Leo. The Acoustical Design of Concert Halls. Building Acoustics, n.1, v.1, p. 3-25, 1994.

BERANEK, Leo. Concert hall acoustics: Recent findings. The Journal of the Acoustical Society of America, n. 139, v. 4, p. 1548-1556, 2016.

BERKON, Eliza. With Just One Full-Time Jazz Club Left In The District, Local Musicians Contemplate Their Future. DCist, 11 mar. 2021. Disponível em: https://dcist.com/story/21/03/11/jazz-clubs-shutterwatershed-moment-for-jazz-musicians/ Acesso: 02 abr. 2021.

CHINEN, Nate. The Blue Whale, Beloved Hub of the Jazz Scene in Los Angeles, Announces Permanent Closure. WGBO.org, 31 dez. 2020. Disponível em: https://www.wbgo.org/music/2020-12-31/the-bluewhale-beloved-hub-of-the-jazz-scene-in-los-angeles-announces-permanent-closure\#stream $/ 0$ Acesso: 02 abr. 2021.

CUGNY, Laurent. Les lieux du jazz, Observatoire Musical Français, 2002, inédito. Disponível em: https://www.laurentcugny.org/textes--bibliographies--master Acesso: 02 abr. 2021.

DENNING, Michael. Noise Uprising: the audiopolitics of a world musical revolution, London/New York, Verso, 2015.

GOPNIK, Adam. Saving Birdland - and Jazz History. The New Yorker,04 mar. 2021. Disponível em: https://www.newyorker.com/culture/cultural-comment/saving-birdland-and-jazz-history Acesso: 02 abr. 2021.

GUZMAN, Richard. Hermosa beaches lighthouse cafe plans to reopen in march under new ownership. Dailybreeze, 02 fev. 2021. Disponível em: https://www.dailybreeze.com/2021/02/02/hermosa-beachslighthouse-cafe-plans-to-reopen-in-march-under-new-ownership/ Acesso: 02 abr. 2021. 
JACOBS, Julia. The Met Opera's Musicians, Unpaid Since April, Are Struggling. The New York Times, 15 March 2021. Disponível em: https://www.nytimes.com/2021/03/15/arts/music/metropolitan-operapandemic.htmlAcessoem: 11 abr 2021.

JASPER, Sandra Acoustic Ecologies: Architecture, Nature, and Modernist Experimentation in West Berlin. Annals of the American Association of Geographers, n.110, v.4, p. 1114-1133, 2020.

JOHNSON, James Listening in Paris: A Cultural History. Berkeley: University of California Press, 1995.

KETTLE, Martin. Interview - Daniel Barenboim: "If I could never conduct a live Ring cycle again, I don't know what I would do". The Guardian, 9 jul. 2020. Disponível em:https://www.theguardian.com/music/2020/jul/09/daniel-barenboim-if-i-could-never-conduct-alive-ring-cycle-again-i-dont-know-what-i-woulddo?fbclid=IwAR01kKSFKu_TQwjupTMz4mx7Bjn5I7V3qjv7JJgV_JxhgECX5F5D1oox-xQ Acesso: 31 jan. 2021.

LEVINE, Lawrence. Highbrow/Lowbrow: the emergence of cultural hierarchy in America. Cambridge: Harvard University Press, 1990.

LYRA de CARVALHO, Frederico. "Excesso musical da pandemia". Lugar Comum, n. 57, abril 2020, p. 234-244.

MAISONNEUVE, Sophie. L'industrie phonographique et la patrimonialisation de la musique dans la première moitié du XXe siècle. Le Temps des Médias - Revue d'histoire, n. 22, juin 2014.

OLCOTT, Emily. "I Remember the Jazz Standard". Blog, 02 dec. 2020. Disponível em: https://emilyolcott.medium.com/i-remember-the-jazz-standard-b1 fab2de8389 Acesso: 02, abr. 2021.

ROUEFF, Olivier. De la légitimité du jazz. Le(s) public(s) de la culture. Paris: Presses de Science Po, 2003, p. 319-360.

SISARIO, Ben; RUSSONELLO, Giovanni. Jazz Lives in Clubs. The Pandemic Is Threatening Its Future. New York Times, 08 set. 2020. Disponível em: https://www.nytimes.com/2020/09/08/arts/music/jazz-clubs-coronavirus.html. Acesso: 02 abr. 2021.

STREECK, Wolfgang. Buying time: the delayed crisis of democratic capitalism. London/New York: Verso, 2017.

THOMPSON, Emily. The soundscape of modernity: architectural acoustics and the culture of listening in America, 1900 - 1933. Cambridge: MIT Press, 2002.

TSIOULCAS, Anastasia. Jazz Standard, One Of New York's Top Clubs, Closes Due To Pandemic. NPR,02 dez, 2020. Disponível em: https://www.npr.org/2020/12/02/941300811/jazz-standard-one-ofnew-yorks-top-clubs-closes-due-to-pandemic Acesso: 02 abr. 2021.

SENNETT, Richard. $O$ declínio do homem público: as tiranias da intimidade. São Paulo: Companhia das Letras, 1988.

YANBEKIAN, Annie. Couvre-feu : trois clubs de jazz parisiens entre combativité et pragmatisme. France tv info, 15 out. 2020. Disponível em: https://www.francetvinfo.fr/culture/musique/jazz/couvrefeu-trois-clubs-de-jazz-parisien-entre-combativite-et-pragmatisme_4142547.html. Acesso: 02/04/2021.

ZUMTHOR, Paul. Performance, recepção, leitura. São Paulo: Cosac Naify, 2007. 